\title{
"Total Surrender and Showing Some Guts": Putting Alternative Medicine on the Map
}

\author{
Gary Tzu* \\ Faculty of Health Sciences, University of Lethbridge, Canada
}

*Corresponding author: Gary Tzu, Professor Emeritus, Faculty of Health Sciences, University of Lethbridge, Canada.
Received Date: October 17, 2019

Published Date: November 27, 2019

\section{Opinion}

About five years ago, at the University of Lethbridge, we hired in the Faculty of Health Sciences, a new Complimentary and Alternative Health Researcher. What was funny to me, as I watched her over the next few months, is that there was no way to distinguish her research agenda from any of the other Health Researchers in the faculty or the university for that matter. The topics seemed very typical to what was being studied in traditional health research with a minor twist. Lots of projects on examining the effectiveness on herbs, vitamins, and supplements using traditional scientific research methodologies. It made me question what does complimentary and alternative even mean [1].

I realized that I had much more experience in the complimentary and alternative health area than most of my colleagues combined as I existed as a non-dual psychologist and researcher in a very traditional scientific materialist academic setting for 20 years. I was truly alternative as non-dual psychology goes beyond body and mind to study the interconnecting energy that goes beyond form, non-dual points to the emptiness, the nothingness, the beingness, consciousness, the unmanifest, the divine energy that goes beyond material form in existence. This was truly a very alternative paradigm to study. Wilber [4] described the three eyes of research as being the eye of flesh- traditional scientific methods, the eye of mind as being phenomenological-hermeneutic research, and the eye of spirit being the mandalic, transpersonal divine research. All of these eyes of research follow the same meta protocol, the following of a set of instructions, a way of apprehending the results, and a communal strand in which results are shared with the community. The lowest eye of flesh tends to run things at typical universities. The eye of mind might be be grunginly accepted Van Manen [3], but still seem somewhat flakey in the eyes of the traditional scientific regime.
Now think if what it is like to exist as a non-dual psychologist professor researcher studying the ancient spiritual wisdom traditions and the pathways to enlightenment in an institution run by scientific materialists who outright deny the existence of spiritual consciousness interconnecting energy and think enlightenment is just a manically induced made up construct. In short, my experience is that you get screwed by the university research establishment and funding agencies all over the place. I published over 60 peer reviewed articles, mostly on unfunded research initiatives meaning I paid for it myself. I published 5 leading edge phenomenological articles on the non-dual awakening into enlightenment process as well as the healing of trauma and the curing of burnout using a nondual approach all for just $\$ 9000$. I receive 30 invitations for papers and presentations and guest editorial ships from around the world a month from healing cancer to changing brain chemistry and neuroplasticity as well as becoming enlightened. I started a nondual psychology peer reviewed journal called Paradoxica which I covered all costs for over the eight years it ran to a tune of $\$ 40,000$ and ran an international conference for 7 of those years in which I lost an extra $\$ 25,000$. The only thing that the university paid for is free morning coffee and snacks and a wine and cheese at the end of each conference.

As well I published two non-dual books From Addiction to Awakening and Awakening Through the Paradox of Darkness [2]. The first one was about the journey of recovery from addictions including healing different developmental levels, recognizing narcissism at the heart of addiction, and seeing the path to spiritual enlightenment can be only met with absolute hopelessness, and total failure hood before the end of seeking arises and there is a falling into totally embracing the now as this is all there is, the eternal now. My second book took off from there, and discussed end of the line problems such as nothing to do and nowhere to go, the dropping 
away of the romantic ideal and the deconstruction of meaning, and the fall into the abyss of nothingness which is totally accepted as the person becomes one with the abyss . Additional issues that could interrupt the enlightenment process are addressed such as sexual trauma as well, hell realm experiences and eternal bewilderment as well as past life experiences.

All of this so a person can come to a place where the separate self falls away and the person becomes the very vastness of existence itself while staying very grounded and working with people from the bottom of the ocean as well as accepting we are eternal citizens that go on and on and we must be ongoing risktakers so we don't end up in some form of spiritual bureaucracy after death and can keep living with passion and intensity as we accept our roles as gatekeepers of this beautiful earth. The sacrifice I had to make was letting go of the university and all that entails as with enlightenment one can only have one master, existence itself. So all of this huge intense journey through academia was met with calamity when my dean hijacked the promotion process to full professor by saying he had read my second book and said it was far too flakey to be a key component of my full professor application, and he said he could not support me at all going ahead with my STP application for full professorship.

He convinced me it would be hopeless to apply. I of course was totally heart broken but through a couple of years of feeling I got the rug pulled out of me and had resultant cancer, I got to a total place of acceptance of all of it including the loss of my full professorship and having to leave the university, cancer, and a whole history of past lives good and bad. Through this total acceptance in the eternal now, I have moved into a deeper, fully embodied enlightenment and realize that my alternative career in non-dual psychology was totally worth it, as I have become fully enlightened and live on the other side and do what I can on this side to help out other beings that they are always already enlightened, they just have to realize it and enjoy.

While the word "complimentary" points to an intervention usually on the same horizontal dimension that the major medical treatment is on Wilber [4], the hugeness of the word "Alternative" can no longer be denied as the great white light, now the midnight, sun shines brightly on all levels. We are now asked to receive the invitation of enlightenment right here right now.

\section{Acknowledgment}

None.

\section{Conflict of Interest}

Author declare no conflict of interest.

\section{References}

1. Tzu G (2014) Beyond Addiction to Awakening.

2. Wilber K (1986) The spectrum of development. In K Wilber, J Engler \& D Brown (Eds.), Transformations of Consciousness.

3. Van Manen M (1990) Researching lived experience: Human science for action centered pedagogy. London Althouse Press.

4. Tzu G (2019) Awakening in the Paradox of Darkness. Victory: Friesen Press. 